Portland State University

PDXScholar

Civil and Environmental Engineering

Undergraduate Honors Theses

Spring 2021

\title{
Maximum Coverage Facility Location Drone Routing Problem with Multiple Trip Stops
}

\section{Marie Roza}

Portland State University

Follow this and additional works at: https://pdxscholar.library.pdx.edu/cengin_honorstheses

Part of the Civil Engineering Commons, and the Transportation Engineering Commons Let us know how access to this document benefits you.

\section{Recommended Citation}

Roza, Marie, "Maximum Coverage Facility Location Drone Routing Problem with Multiple Trip Stops" (2021). Civil and Environmental Engineering Undergraduate Honors Theses. 13.

https://doi.org/10.15760/honors.1148

This Thesis is brought to you for free and open access. It has been accepted for inclusion in Civil and Environmental Engineering Undergraduate Honors Theses by an authorized administrator of PDXScholar. Please contact us if we can make this document more accessible: pdxscholar@pdx.edu. 
MAXIMUM COVERAGE FACILITY LOCATION DRONE ROUTING PROBLEM WITH

MULTIPLE TRIP STOPS

BY

MARIE ROZA

A thesis submitted in partial fulfillment

of the requirement for the degree of

\section{BACHELOR OF SCIENCE}

IN

CIVIL AND ENVIRONMENTAL ENGINEERING

Thesis Advisor:

Avinash Unnikrishnan

Portland State University

(C)2021 


\section{ACKNOWLEDGMENTS}

I would like to express my sincere gratitude to my advisor, Dr. Avinash Unnikrishnan, for introducing me to linear optimization modeling and for his continuous support during my research and the development of my formulation. I'm extremely grateful for this experience and have gained many new skills during this past year of research and development.

I would also like to thank Darshan Chauhan for his support and help over the past year. I was able to learn so much from his previous work and publications, and it was an honor to have the opportunity to expand upon his work. Also, I would like to extend a big thank you to both Dr. Avi and Darshan for always being ready to answer my questions, no matter how many I asked.

I would like to thank the PSU CEE Department for offering me the opportunity to work on an undergraduate thesis and for supporting me throughout this journey.

I would also like to thank the National Science Foundation, who supported my research through Grant 1826337: "Collaborative Research: Real-Time Stochastic Matching Models for Freight Electronic Marketplace.”

Finally, I would like to express my gratitude to my friends and family who have motivated me to persevere throughout this degree - I would not be where I am today without their support, patience, and encouragement. 


\begin{abstract}
Integer linear optimization can be used to formulate routing problems as models to find optimal solutions given a set of inputs and constraints. In this research, Chauhan et al.'s publication, "Maximum coverage capacitated facility location problem with range constrained drones," is expanded upon by modeling a facility location problem with two-to-one drone deliveries. The model analyzes a set of potential facilities that are available to meet the demands of a set of demand points. The drone delivery routes are modeled with the assumption that each opened facility is assigned one drone that can fulfill up to two demand points' demands per trip. The objective of this model is to locate the open facilities and serviced demand points while meeting drone battery constraints and maximizing demand coverage. This research explores the results of this model for a set of facilities and demand points in the Portland Metropolitan Area based on different facility and battery constraint scenarios.
\end{abstract}




\section{TABLE OF CONTENTS}

1.0 INTRODUCTION .......................................................................................................................................... 1

2.0 LITERATURE REVIEW ..................................................................................................... 2

3.0 PROBLEM DESCRIPTION .......................................................................................................

4.0 NUMERICAL ANALYSIS ............................................................................................................... 9

4.1 ResUlts WITH VARYing MaXIMUM OPEN FACILITIES AND 100\% BATTERY CAPACITY............................... 11

4.2 RESULTS WITH VARYING MAXIMUM OPEN FACILITIES AND 150\% BATTERY CAPACITY............................... 12

4.3 RESULTS WITH VARYING MAXIMUM OPEN FACILITIES AND ONE-STOP TRIPS................................................ 14

4.4 RESULTS WITH 25 MAXIMUM OPENED FACILITIES AND VARIOUS BATTERY \& LOAD CAPACITIES................ 16

5.0 CONCLUSION ...................................................................................................................................................... 18

6.0 REFERENCES .................................................................................................................................................. 19

APPENDIX _.................................................................................................................................................................... 21

APPENDIX A: Model Code - MulTIPLE TRIP STOPS ……………………………………………………. 21 


\section{LIST OF TABLES}

Table 1: Drone Parameters.......................................................................................................................... 10

Table 2: Comparison of demand served with varying number of maximum open facilities ..................................... 11

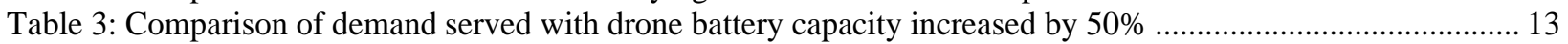

Table 4: Comparison of demand served with trips limited to one stop .................................................................. 14

Table 5: Comparison of demand served with 25 open facilities and varying battery and load capacities .................. 16 


\section{LIST OF FIGURES}

Figure 1: Model Results - 25 Open Facilities, 100\% Battery Capacity ................................................................. 11

Figure 2: Served Demand Points - 25 Open Facilities, 100\% Battery Capacity..................................................... 12

Figure 3: 25 Open Facilities, 150\% Battery Capacity..................................................................................... 13

Figure 4: 25 Open Facilities Limited to One-Stop Trips ......................................................................... 15

Figure 5: 25 Open Facilities, 125\% Battery and Payload Capacities .......................................................... 17

Figure 6: 25 Open Facilities, 150\% Battery and Payload Capacities ............................................................... 17 


\subsection{INTRODUCTION}

Drone deliveries are vital for meeting emergency service demands. There are often scenarios where medical assistance is required but cannot reach the injured individuals, or cannot reach them in a timely manner (Konert et al., 2019). Drones, however, are able to autonomously fly into these environments to provide medical equipment while waiting for help to arrive (Messar et al., 2018). These devices can carry life-saving products, such as blood (Ling \& Draghic, 2019), first-aid kits and medication (Thiels et al., 2015), cardiac defibrillators (Mermiri et al., 2020), and other medical equipment. Over the past year, it has become increasingly apparent that drone deliveries are not only vital for meeting the needs of individual emergency events, but also for providing solutions for worldwide crises, like the COVID-19 pandemic (Kunovjanek \& Wankmüller, 2021). Zipline, a US-based startup that provides autonomous aircraft delivery services, has been delivering COVID-19 supplies like PPE to hospitals in Ghana and transporting test samples to laboratories (Bailey, 2021). The medical supplies can be requested by doctors within a range of 50 miles of Zipline's distribution centers. After the supplies are requested, the drones arrive within 30 minutes to deliver them, dropping the parcel from the sky with a parachute attached (Bailey, 2021). According to CNN Business, over 60,000 units of blood, medicine, and vaccines have been transported by Zipline's autonomous drones as of March 2021 (Bailey, 2021). One study completed by Messar et al. evaluated the delivery time of a drone carrying medical equipment to a remote location compared to delivery of supplies on foot or on a wheeled vehicle. The study found that delivery by drone took a total of about 21 minutes, while delivery on foot and on a vehicle would have taken 5.1 hours and 61.35 minutes, respectively (Messar et al., 2018). It is evident that the implementation of autonomous drone deliveries for delivering medical supplies can often be more effective than relying on vehicular deliveries. To complete these deliveries, the trips and demand points must be pre-determined, specifying exactly where the drone will travel to ensure that the demand is met. In this paper, optimization is utilized to determine optimal routes for drones by composing a multiple integer linear programming model. The results from this model determine the maximum possible demand that can be served, based on the available number of distribution centers (facilities), their locations, and several other constraints. 


\subsection{LITERATURE REVIEW}

This paper expands upon Darshan Chauhan et al.'s paper, "Maximum coverage capacitated facility location problem with range constrained drones" (Chauhan et al., 2019). Chauhan et al.'s paper studies the routing of drones from facilities to demand points, with capacitated facility locations. Additionally, the paper explores drone allocation, where a set number of drones are available for all of the facility locations and the model then allocates these drones to each facility before determining facility coverage of demand points (Chauhan et al., 2019). Utilizing the one-to-one trip model, Chauhan et al.'s formulation models multiple one-to-one drone trips, where the rangeconstrained drones travel from their assigned facility locations, to a single demand point, and then back, before heading out on another trip if the remaining battery permits (Chauhan et al., 2019). In this paper, the maximum coverage facility location problem is expanded upon by incorporating range-constrained drones and multiple stop delivery trips. Specifically, the multiple stop delivery trips indicate that each drone can fulfill either one or two deliveries on a trip, depending on the battery consumption of that specific route. The facilities are not modeled as capacitated locations, meaning that there is no limit to how much demand each opened facility can supply. This paper also does not include drone allocation in the model; it is assumed that only one drone is located at each facility that is opened.

Church \& Revelle discuss maximizing the demand covered by locating facilities in "Maximal Covering Location Problem" (Church \& Revelle, 1974). Their paper focuses on maximizing the demand that is served by the facilities rather than minimizing the cost of production or service. By optimizing maximum demand served, the model prioritizes public facility location needs, where priorities may lie with the social aspect rather than the economic impact. Church \& Revelle also incorporate a distance or time limitation on the objective value, modelling with a set of facilities that are within a coverage radius from demand points (Church \& Revelle, 1974). This paper does not put a limit on the distance that a demand point should be located from a facility. However, the range-constrained drones that are modelled in this paper act as distance constraints, because demand points that are located further away from potential facility locations will result in greater battery consumption and are less likely to be covered than demand points located closer to facilities. The maximum coverage characteristic of Church \& Revelle's work is implemented in

this paper - the objective of this paper's formulation is to maximize the cumulative demand served by the drones. 
Dayarian et al. discuss routing of UAVs, or drones, for home deliveries of goods. The paper discusses the VRPDR, a vehicle routing problem with drone resupply where same-day delivery of goods to customers is completed by delivery trucks that are resupplied by drones. The study looked at a system consisting of one drone and one delivery truck. After completing the study, the findings displayed that utilizing drones greatly reduced the economic cost and time involved in making deliveries. Drone deliveries were much faster than those fulfilled by trucks. Dayarian et al.'s study considers a service time guarantee as a constraint and makes the assumption that all packages carried by drones have the same weight. This paper, however, does not incorporate any time constraints. It also differs from Dayarian et al.'s study because each demand point has a different package weight, and the drones can carry and deliver up to two packages per trip. Finally, this paper does not incorporate drone resupply; instead, it is assumed that no delivery trucks are used and delivery is completed by drones only (Dayarian et al., 2017).

Campbell et al.'s paper, "Strategic Design for Delivery with Trucks and Drones," explores the concept of "hybrid truck-drone deliveries" for commercial distribution. This concept proposes delivery of packages by autonomous drones that are on trucks traveling a delivery route. The drones leave the trucks to deliver the packages and then fly back to pick up new packages. Campbell et al.'s proposed model assumes that both the drones and the trucks are making deliveries throughout the route, and it is constrained by considering that drones only carry one package per trip. This paper, however, considers delivery by drones only and assumes that drones can carry up to two packages per trip. The focus of the hybrid model was economic, aiming to reduce delivery costs rather than to meet a specific, quick delivery time window. This paper does not consider economic constraints - it proposes autonomous medical equipment deliveries, with a focus on maximizing the demand served rather than reducing delivery costs. Campbell et al. also analyzed both rural and suburban regions, whereas this paper analyzes deliveries in an urban metropolitan area (Campbell et al., 2017).

Focusing on drone battery energy consumption, Dorling et al. discuss two multi-trip vehicle routing problems that focus on reducing operation costs and delivery times, respectively. Their research emphasizes the importance of incorporating payload weight and battery weight when considering energy consumption of drones. Dorling et al. discovered that including payload and battery weight affects the drone's flight time and that these factors should be included in models 
to ensure that the drone routing problem solutions are applicable. This paper also includes drone payload and battery weight constraints in the facility location drone routing problem. Dorling et al.'s paper evaluates single-load drone deliveries, where the drone delivers one package per trip and then returns to the facility to pick up the next package (Dorling et al., 2017). This paper incorporates weight constraints, but it does so with multi-stop drone trips. The research presented below involves drones that leave the facility with up to two packages, meaning that they can make up to two stops per trip. There do not seem to be many previous publications that evaluate the significance of drone trip routing problems with two-stop, or multi-stop, trips. 


\subsection{PROBLEM DESCRIPTION}

This formulation expands on Chauhan et al.'s publication, "Maximum coverage capacitated facility location problem with range constrained drones." This maximum coverage multiple facility location problem relies on an input of a set of facilities that contain medical equipment, a set of demand points that require this equipment, and the level of demand at each of the demand points. Additionally, the formulation outlined in this paper assumes that only one drone can be located at every potential facility location. The drone at each location is battery constrained, and the battery consumption is a function of the load that the drone is carrying, as well as the distance that it needs to travel. The battery consumption utilized in this formulation is modeled using Figliozzi's equation in "Lifecycle modeling and assessment of unmanned aerial vehicles (drones) co2 emissions", and consists of the following components (Figliozzi, 2017):

$$
b=\frac{(m+w) g d}{\eta \theta_{s}}=(m+w) \lambda d
$$

Additionally, it was assumed that each drone would make up to two stops per trip: a single trip consists of the drone starting at an open origin facility location, where it would be loaded with the load for the trip. The drone would then leave the facility and complete its first stop, where the load for the first demand point would be dropped off once it landed. If the drone was able to make a second stop, it would complete the second stop at the second demand point to drop off that demand point's load. Finally, the drone would return back to its original facility and the trip, or route, would be completed. For the purpose of this formulation, it was assumed that if the drone was carrying demand for two demand points, the load for the second stop would not be removed by civilians at the first stop. This multiple stop model was incorporated by including two binary variables, $x_{i j}$ and $a_{i j}$, that would indicate the demand point's placement within the delivery trip. The purpose of $x_{i j}$ was to relay the demand points that would be visited first on a trip - if $x_{i j}$ was one, the demand point $i \in I$ would be covered first by the facility $j \in J$. The purpose of $a_{i j}$ was to relay the demand points that would be visited second on a trip - if $a_{i j}$ was one, the demand point $i \epsilon I$ would be covered second by the facility $j \in J$.

The formulation for this mixed integer linear maximum coverage facility location routing problem with multiple trip stops is listed below: 


\section{Nomenclature Sets}

I Set of all demand locations

$J \quad$ Set of all potential facility locations

\section{Indices}

$i \in I \quad i$ th demand point in set of all demand points

$k \in I \quad k$ th demand point in set of all demand points

$j \in J \quad j$ th facility location in set of all facility locations

\section{Parameters}

$\eta \quad$ power transfer efficiency

$\theta_{s} \quad$ lift-to-drag ratio

$m_{b} \quad$ UAV battery mass

$m_{p} \quad$ payload capacity of drone $[\mathrm{kg}]$

$m_{t} \quad$ UAV mass tare, without battery \& load

$m \quad m_{b}+m_{t}$

$g$ acceleration due to gravity

$\lambda \quad \frac{g}{\eta \theta_{s}}$

$w_{i} \quad$ demand at demand point $i \in I$

$d 1_{i j} \quad$ distance between facility location $j \in \mathrm{J}$ and demand point $i \in I$

$d 2_{i k} \quad$ distance between demand points $i \in I$ and $k \in I$

$B \quad$ battery capacity of drone and each facility

$p \quad$ maximum number of opened facilities

\section{Decision Variables}

$y_{j}$ - variable determining open facilities; the variable takes a value of 1 if facility $j \epsilon J$ is opened and a value of 0 if not

$x_{i j}$ - variable determining if demand point $i \epsilon I$ is the first stop covered by facility $j \epsilon J$; the variable takes a value of 1 if demand point $i \in I$ is the first stop covered by $j \in J$ and a value of 0 if not 
$a_{i j}$ - variable determining if demand point $i \epsilon I$ is the second stop covered by facility $j \epsilon J$; the variable takes a value of 1 if demand point $i \in I$ is the second stop covered by $j \in J$ and a value of 0 if not

$\alpha_{k i j}$ - the variable takes a value of 1 if demand point $k$ is served after demand point $i$ using drone launched from facility $j$ and a value of 0 otherwise

\section{Objective}

$$
\max \sum_{i \in I} \sum_{j \in J} w_{i}\left(x_{i j}+a_{i j}\right)
$$

\section{Constraints}

$$
\begin{aligned}
& \sum_{j \in J} y_{j} \leq p \\
& \sum_{j \in J} x_{i j}+a_{i j} \leq 1, \forall i \in I \\
& \sum_{i \in I} x_{i j} \leq y_{j}, \forall j \in J \\
& \sum_{i \in I} a_{i j} \leq \sum_{i \in I} x_{i j}, \forall j \in J \\
& \sum_{i \in I} w_{i} *\left(x_{i j}+a_{i j}\right) \leq m_{p}, \forall j \in J \\
& \sum_{i \in I}\left[\left(2 m+w_{i}\right) \lambda d 1_{i j} x_{i j}+\sum_{k \in I}\left\{\begin{array}{c}
\left(w_{k}\right) \lambda d 1_{i j}+\left(m+w_{k}\right) \lambda d 2_{i k} \\
+m \lambda d 1_{k j}-m \lambda d 1_{i j}
\end{array}\right\} \alpha_{k i j}\right] \leq B y_{j}, \forall j \in J \quad \text { [6] } \\
& \alpha_{k i j} \leq x_{i j}, \forall k \in I, i \in I, j \in J \\
& \alpha_{k i j} \leq a_{k j}, \forall k \in I, i \in I, j \in J \\
& \alpha_{k i j} \geq x_{i j}+a_{k j}-1, \forall k \in I, i \in I, j \in J \\
& \alpha_{k i j} \geq 0, \forall k \in I, i \in I, j \in J \\
& x_{i j}, a_{i j} \in\{0,1\}, \forall i \in I, j \in J
\end{aligned}
$$




$$
y_{j} \in\{0,1\}, \quad j \in J
$$

The objective ensures that the demand covered by drone delivery trips will be maximized. Constraint [1] ensures that no more than $p$ facilities are opened. Constraint [2] ensures that each demand point is covered at most once by a facility. Constraint [3] ensures that first stop demand points are only assigned to facilities that are open. Constraint [4] ensures that second stop demand points are only assigned if a first stop demand point is assigned to a facility. Constraint [5] ensures that the load carried by the drone does not exceed the payload capacity of the drone. Constraint [6] ensures that the battery used on a route is less than the drone's battery capacity. Constraints [7], [8], [9], and [10] are part of constraint [6]'s linearization, where $\alpha_{k i j}$ takes a value of one if $x_{i j}$ and $a_{i j}$ are both one, and a value of zero otherwise. Constraint [11] ensures that the demand point decision variables are binary, set to a value of either zero or one. Constraint [12] ensures that the facility decision variable is binary, set to a value of either zero or one. 


\subsection{NUMERICAL ANALYSIS}

The network was generated in Chauhan et al.'s "Maximum coverage facility location problem with range constrained drones." All locations involved in the analysis are based in the Portland Metropolitan Area. There were a total of 122 demand points and 104 potential facility locations. The U.S. Census Bureau uses zip code tabulated areas (ZCTAs) as "generalized areal representations" of regions that are serviced by the U.S. Postal Service by zip code areas (U.S. Census Bureau, 2020). These ZCTAs were used to generate the demand point locations by selecting the centers of ZCTAs as demand points. The potential facility locations were placed at various community centers in the Portland Metropolitan Area. Community centers are efficient facility locations because they are available for public use, which would be necessary in the case of a public emergency when demand of medical equipment is high. Community centers are also capable of keeping equipment due to their size, and are large enough to accommodate drone takeoff and landing. Additionally, the potential facility locations and demand points in the facility were analyzed to ensure that there was no overlap between locations (Chauhan et al., 2019).

Each demand point was assigned a demand or payload value, which was randomly generated with a discrete uniform distribution. The distribution varied between payload values of $1 \mathrm{~kg}$ to $5 \mathrm{~kg}$ and was allocated at intervals of $0.25 \mathrm{~kg}$. The total demand available to be served was $366.5 \mathrm{~kg}$ (Chauhan et al., 2019). In this problem's analysis, values of 15, 25, and 60 were chosen as the maximum number of open facilities. Euclidean distances were used to define the distance between facilities and demand points or between two demand points because drones are able to travel through the air and do not require road-like paths or routes. However, the operation of drones is currently restricted by the FAA in certain airspaces - these restricted areas were not considered in this paper.

Finally, Figliozzi's work, "Lifecycle modeling and assessment of unmanned aerial vehicles (Drones) $\mathrm{CO}_{2}$ e emissions" provides several drone parameters that were used to develop the constraints for the optimization model in this paper (Figliozzi, 2017). The parameters are detailed in Table 1: 
Table 1: Drone Parameters

\begin{tabular}{|c|c|}
\hline Power Transfer Efficiency $(\eta)$ & 0.66 \\
\hline Lift-to-drag Ratio $\left(\theta_{s}\right)$ & 3.5 \\
\hline Tare Weight + Battery Weight $(m)$ & $10.1 \mathrm{~kg}$ \\
\hline Maximum Payload & $5 \mathrm{~kg}$ \\
\hline Battery Capacity & $777 \mathrm{Wh}$ \\
\hline Battery Safety Factor & $1.25=80 \%$ of maximum battery capacity \\
\hline
\end{tabular}

The mixed integer linear maximum coverage facility location routing problem with multiple stops was solved using Gurobi, a commercially available MIP solver. The models were solved on a 2019 MacBook Air with Intel Core i5 CPU 1.6 GHz, 4 cores, 8 logical processors and 8 GB of RAM.

Several model scenarios were tested to see how varying the maximum number of opened facilities or drone capacities affected the total demand served. 


\subsection{Results with Varying Maximum Open Facilities and 100\% Battery Capacity}

For a maximum of 15 opened facilities with a drone battery capacity of $777 \mathrm{Wh}$, the total demand served was $75 \mathrm{~kg}$ with a coverage of $20.46 \%$ (Table 2). The total distance traveled in this scenario was 233.56 miles, with a total of 15 first stops and 10 second stops on the drone routes. For a maximum of 25 opened facilities, the total demand served was $125 \mathrm{~kg}$ with a coverage of $34.11 \%$. The total distance traveled was 443.33 miles, with a total of 25 first stops and 20 second stops.

Table 2: Comparison of demand served with varying number of maximum open facilities

\begin{tabular}{|c|c|c|c|c|c|c|}
\hline $\begin{array}{c}\text { Maximum } \\
\text { number of } \\
\text { opened } \\
\text { facilities, } \mathrm{p}\end{array}$ & $\begin{array}{c}\text { Battery } \\
\text { Capacity, B } \\
{[\mathrm{Wh}]}\end{array}$ & $\begin{array}{c}\text { Total } \\
\text { Demand } \\
\text { Served }[\mathrm{kg}]\end{array}$ & Coverage & $\begin{array}{c}\text { Distance } \\
\text { Traveled } \\
{[\mathrm{miles}]}\end{array}$ & $\begin{array}{c}\text { Total } \\
\text { Number of } \\
\text { First Stops }\end{array}$ & $\begin{array}{c}\text { Total } \\
\text { Number of } \\
\text { Second } \\
\text { Stops }\end{array}$ \\
\hline 15 & 777 & 75 & $20.46 \%$ & 233.56 & 15 & 10 \\
\hline 25 & 777 & 125 & $34.11 \%$ & 443.33 & 25 & 20 \\
\hline 60 & 777 & 278.5 & $75.99 \%$ & 915.27 & 60 & 32 \\
\hline
\end{tabular}

Figure 1 displays the coverage if 25 facilities were opened and drone battery capacity was at $100 \%$. There is a cluster of serviced demand points within Portland's city limits (outlined below) along with demand points located at further distance from the region's center.

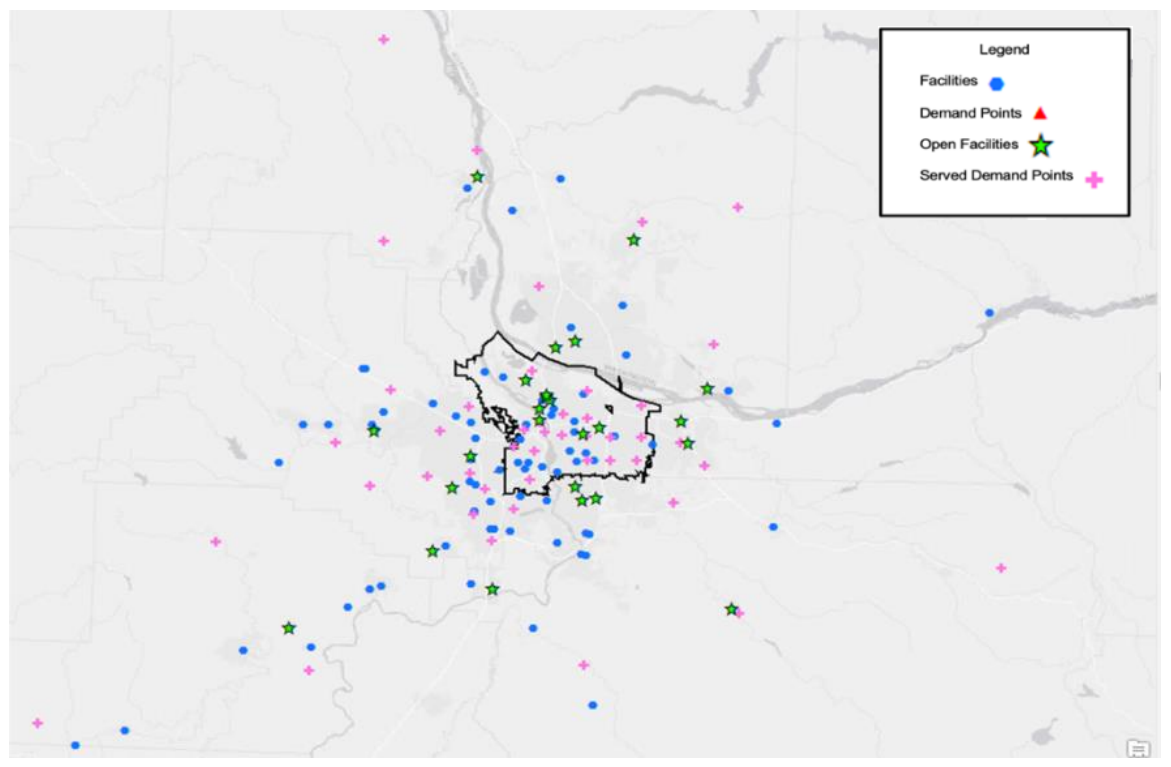

Figure 1: Model Results - 25 Open Facilities, 100\% Battery Capacity 
Figure 2 displays the serviced demand points compared to all possible demand point locations. This represents the demand coverage of $34.11 \%$.

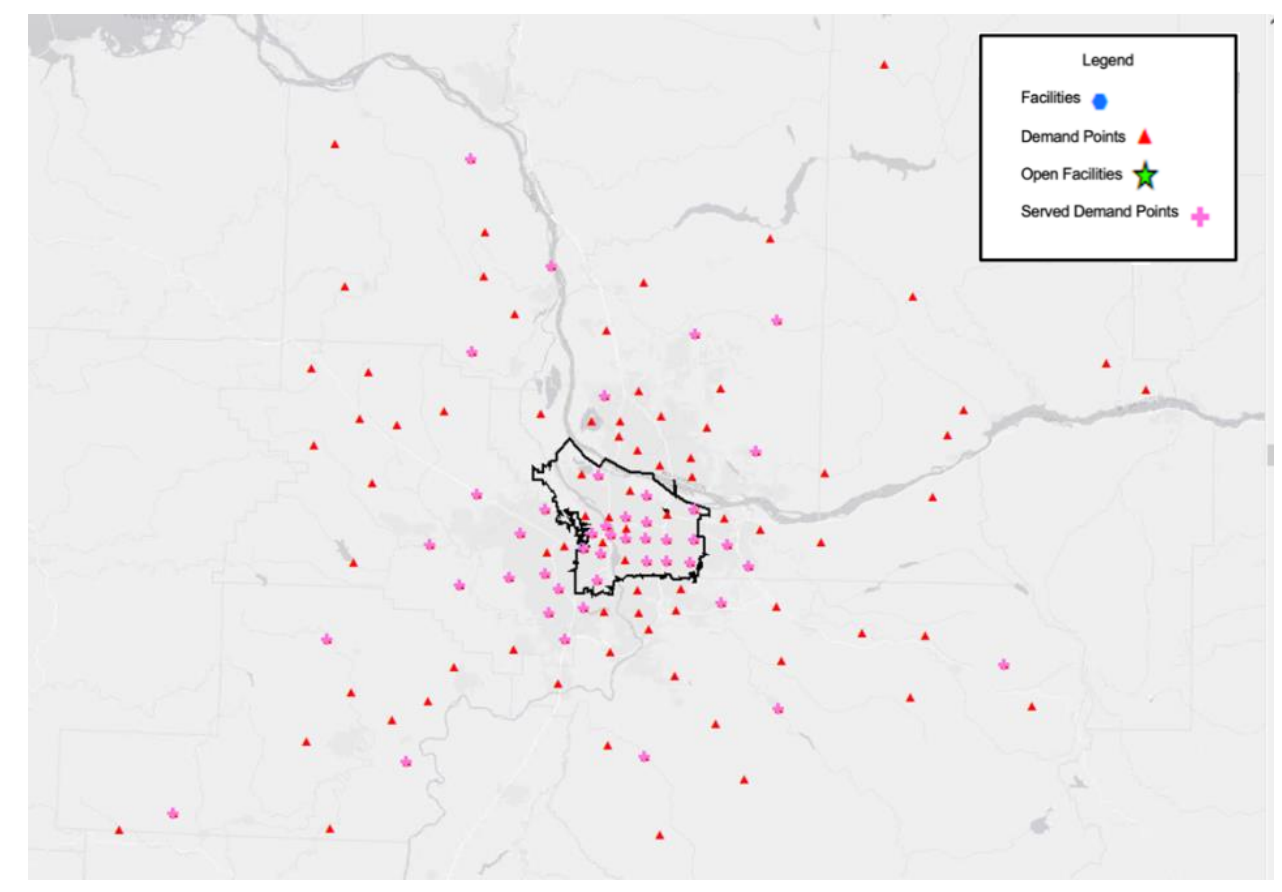

Figure 2: Served Demand Points - 25 Open Facilities, 100\% Battery Capacity

Additionally, a maximum of 60 opened facilities with a battery capacity of $777 \mathrm{Wh}$ resulted in a demand coverage of $76 \%$. This result indicates that opening $58 \%$ of the total number of facilities with drones capable of carrying two packages allows for coverage of more than three-fourths of the total demand. In this scenario, the total distance covered was 915.27 miles.

\subsection{Results with Varying Maximum Open Facilities and 150\% Battery Capacity}

The demand coverage results were similar when comparing the $100 \%$ battery capacity and $150 \%$ battery capacity scenarios (Table 3). For a maximum of 15 opened facilities with a drone battery capacity increase of $50 \%$, total demand coverage remained constant at $20.46 \%$. However, the total distance traveled with a battery capacity of $150 \%, 358.39$ miles, was $53 \%$ greater than the total distance traveled with a battery capacity of $100 \%, 233.56$ miles. 
Table 3: Comparison of demand served with drone battery capacity increased by $\mathbf{5 0 \%}$

\begin{tabular}{|c|c|c|c|c|c|c|}
\hline $\begin{array}{c}\text { Maximum } \\
\text { number of } \\
\text { opened } \\
\text { facilities, } \mathrm{p}\end{array}$ & $\begin{array}{c}\text { Battery } \\
\text { Capacity, B } \\
{[\mathrm{Wh}]}\end{array}$ & $\begin{array}{c}\text { Total } \\
\text { Demand } \\
\text { Served }[\mathrm{kg}]\end{array}$ & Coverage & $\begin{array}{c}\text { Distance } \\
\text { Traveled } \\
\text { [miles] }\end{array}$ & $\begin{array}{c}\text { Total } \\
\text { Number of } \\
\text { First Stops }\end{array}$ & $\begin{array}{c}\text { Total } \\
\text { Number of } \\
\text { Second } \\
\text { Stops }\end{array}$ \\
\hline 15 & 1166 & 75 & $20.46 \%$ & 358.39 & 15 & 10 \\
\hline 25 & 1166 & 125 & $34.11 \%$ & 618.79 & 25 & 20 \\
\hline 60 & 1166 & 286.75 & $78.24 \%$ & 1389.23 & 60 & 37 \\
\hline
\end{tabular}

It is evident that including drone battery parameters is vital for accurate routing solutions drones with increased battery capacities are able to cover a significantly greater range between demand points. This is important when delivery of medical equipment is considered, because it may be likely that only a few open facilities will need to serve a large variety of demand points during a public emergency. The model with 25 maximum opened facilities resulted in total demand coverage of $34.11 \%$ (Figure 3) and a total distance traveled of 1618.79 miles, a value almost $40 \%$ greater than the distance traveled with a battery capacity of $777 \mathrm{Wh}$.

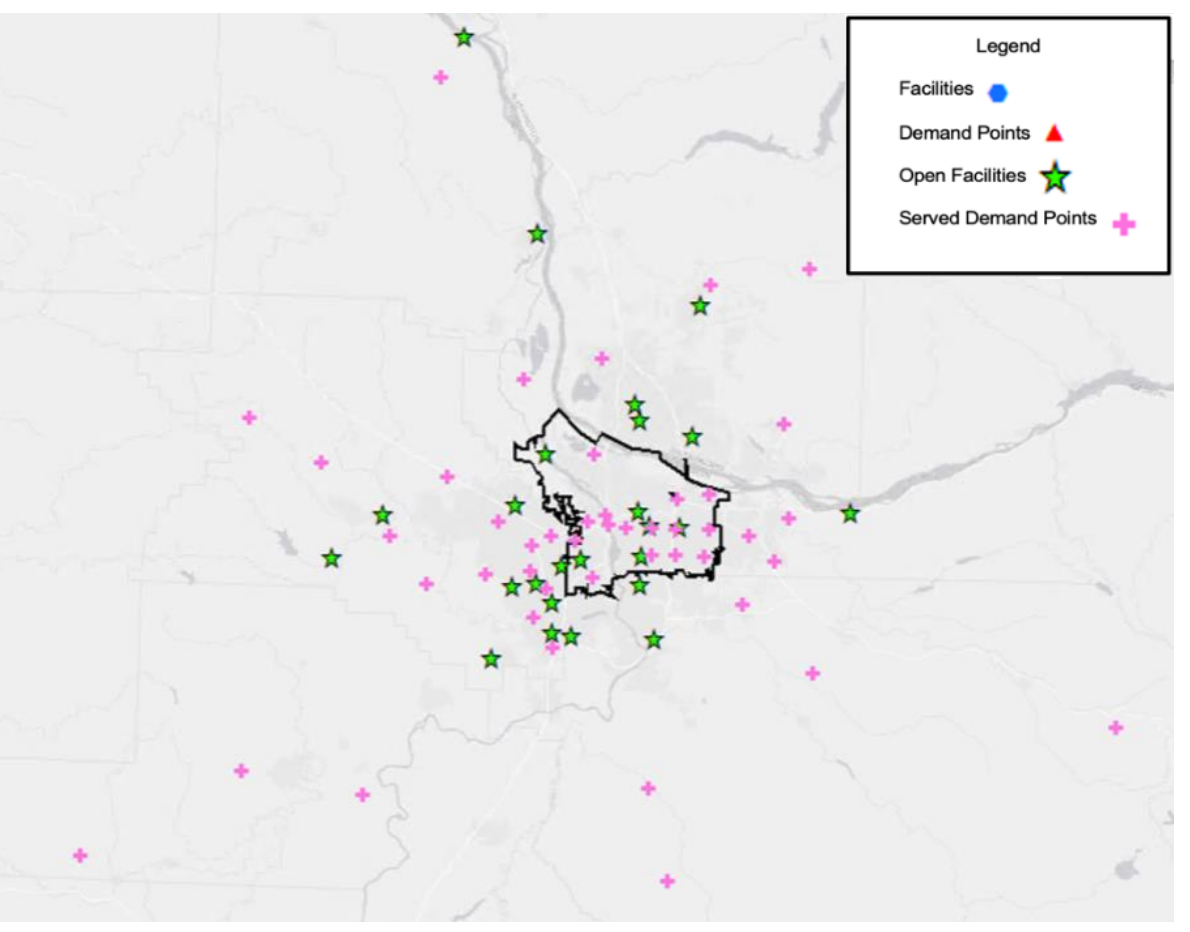

Figure 3: 25 Open Facilities, 150\% Battery Capacity 
After analysis of the results, it was clear that the expanded battery capacity led to drones fulfilling demand points located further away than in the original model scenario. However, demand coverage was not changing significantly due to the payload capacity of drones. The demand values ranged from $1 \mathrm{~kg}$ to $5 \mathrm{~kg}$, and with a payload limit of $5 \mathrm{~kg}$ per drone, the demand point combinations with a summed payload of less than $5 \mathrm{~kg}$ were limited.

\subsection{Results with Varying Maximum Open Facilities and One-Stop Trips}

To compare the results of a model with two stops per trip to a model with only one stop per trip, the $a_{i j}$ variable's upper and lower bounds were set to zero. This indicated that facilities were limited to fulfilling first-stop demand points and would not be assigned second-stop demand points. The battery capacity was also maintained at $100 \%$. In this one-stop trip scenario, a maximum of 15 opened facilities led to a total demand coverage of $19.37 \%$, only $1.1 \%$ lower than demand covered by multi-stop trips (Table 4). When the model was assigned a maximum of 25 open facilities, the total demand coverage was $30.83 \%$ with one-stop trips, and $34.11 \%$ with multistop trips. The difference in coverage between these two trip structures was 3.3\%. Finally, with a maximum of 60 open facilities and single-stop trips, the model's total demand coverage decreased to $63.3 \%$. This was $12.7 \%$ less than the multi-stop trip coverage.

Table 4: Comparison of demand served with trips limited to one stop

\begin{tabular}{|c|c|c|c|c|c|c|}
\hline $\begin{array}{c}\text { Maximum } \\
\text { number of } \\
\text { opened } \\
\text { facilities, }\end{array}$ & $\begin{array}{c}\text { Battery } \\
\text { Capacity, B } \\
{[\mathrm{Wh}]}\end{array}$ & $\begin{array}{c}\text { Total } \\
\text { Demand } \\
\text { Served }[\mathrm{kg}]\end{array}$ & Coverage & $\begin{array}{c}\text { Distance } \\
\text { Traveled } \\
\text { [miles] }\end{array}$ & $\begin{array}{c}\text { Total } \\
\text { Number of } \\
\text { First Stops }\end{array}$ & $\begin{array}{c}\text { Total } \\
\text { Number of } \\
\text { Second } \\
\text { Stops }\end{array}$ \\
\hline 15 & 777 & 71 & $19.37 \%$ & 196.72 & 15 & 0 \\
\hline 25 & 777 & 113 & $30.83 \%$ & 356.26 & 25 & 0 \\
\hline 60 & 777 & 232 & $63.30 \%$ & 902.64 & 60 & 0 \\
\hline
\end{tabular}


Figure 4 displays the results of opening a maximum of 25 facilities and permitting only singlestop delivery trips. The visual effectively portrays the lower quantity of covered demand points when compared to multi-stop trip scenarios - a total of 45 demand points where covered when multiple stops were opened up on drone delivery routes. However, there were only 25 demand points covered in the one-stop trip model analysis. This model allocated more battery and load capacity per demand point due to the reduced number of trips. This meant that demand points located further away from facilities, or ranging higher in demand value, were still likely to be served.

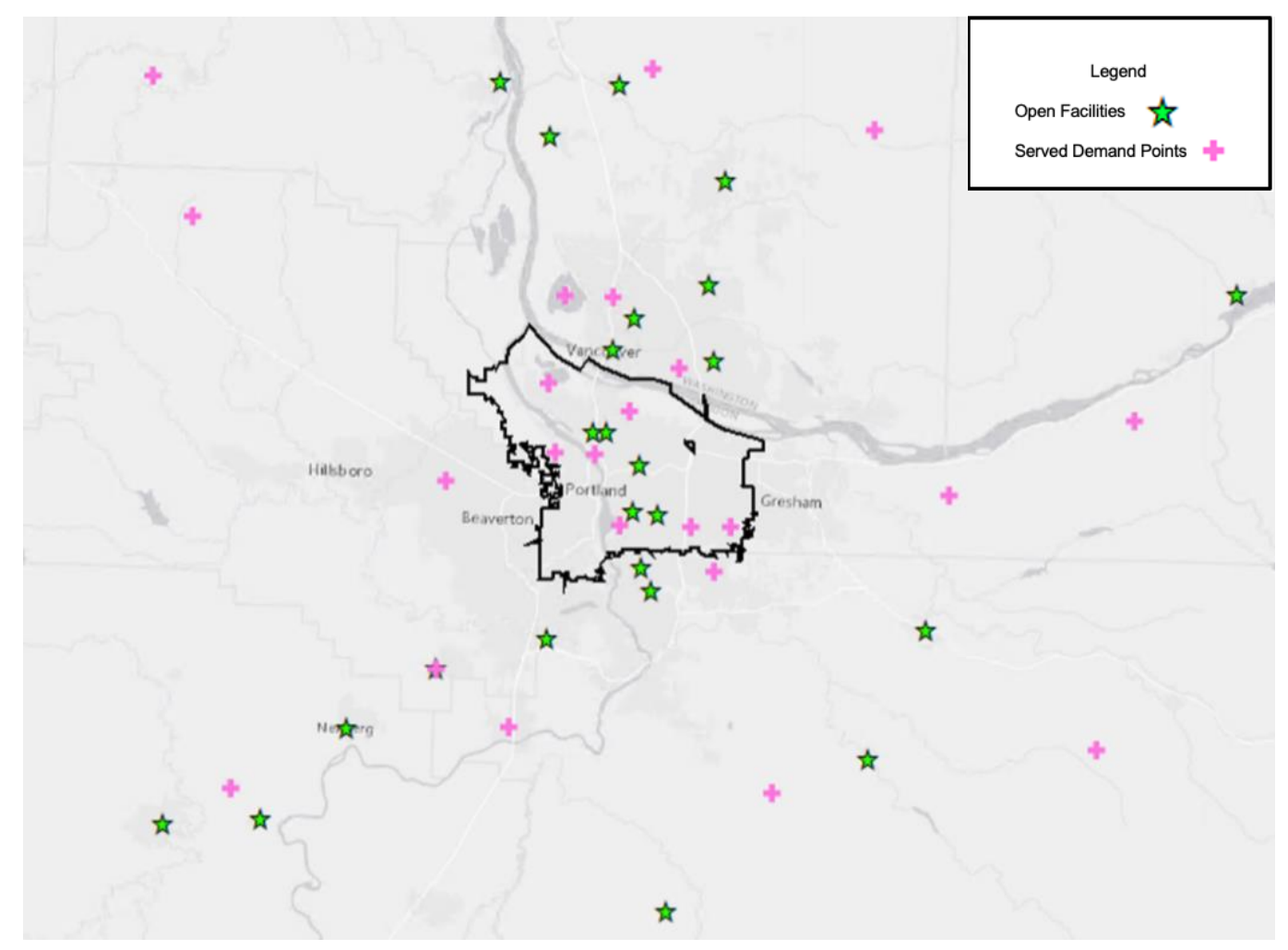

Figure 4: 25 Open Facilities Limited to One-Stop Trips

Due to the insignificant change in demand coverage with increasing battery capacity, a final model adjustment was completed to examine the effects of increased payload capacities on demand coverage improvements. 


\subsection{Results with 25 Maximum Opened Facilities and Various Battery \& Load Capacities}

In the final model, both battery and payload capacities were incrementally increased to observe changes in demand coverage and multi-stop trips. The number of maximum open facilities was maintained at 25 . Initially, the battery capacity and payload capacity were each increased by $25 \%$. This resulted in a battery capacity of $971.25 \mathrm{Wh}$ and a payload capacity of $6.25 \mathrm{~kg}$ (Table 5). Increasing both capacities by $25 \%$ increased the total demand coverage by $8.5 \%$, while increasing both capacities by $50 \%$ led to an increase of $16.6 \%$ in demand coverage. This increase in coverage was significantly greater than the increase related to an improvement in battery capacity alone.

Table 5: Comparison of demand served with 25 open facilities and varying battery and load capacities

\begin{tabular}{|c|c|c|c|c|c|c|c|}
\hline $\begin{array}{c}\text { Maximum } \\
\text { number of } \\
\text { opened } \\
\text { facilities, } \mathrm{p}\end{array}$ & $\begin{array}{c}\text { Battery } \\
\text { Capacity, } \\
\mathrm{B}[\mathrm{Wh}]\end{array}$ & $\begin{array}{c}\text { Payload } \\
\text { Capacity, } \\
\mathrm{m}_{\mathrm{p}}[\mathrm{kg}]\end{array}$ & $\begin{array}{c}\text { Total } \\
\text { Demand } \\
\text { Served } \\
{[\mathrm{kg}]}\end{array}$ & Coverage & $\begin{array}{c}\text { Distance } \\
\text { Traveled } \\
{[\text { miles] }}\end{array}$ & $\begin{array}{c}\text { Total } \\
\text { Number of } \\
\text { First Stops }\end{array}$ & $\begin{array}{c}\text { Total } \\
\text { Number of } \\
\text { Second } \\
\text { Stops }\end{array}$ \\
\hline 25 & 777 & 5 & 125 & $34.11 \%$ & 443.33 & 25 & 20 \\
\hline 25 & 971.25 & 6.25 & 156.25 & $42.63 \%$ & 545.87 & 25 & 25 \\
\hline 25 & 1166 & 7.5 & 185.75 & $50.68 \%$ & 617.15 & 25 & 25 \\
\hline
\end{tabular}

Notably, the number of trips with multiple trip stops also increased; when original capacities were maintained, a total of 20 trips out of 25 total trips were routed to two stops. This resulted in a total of 45 served demand points. However, increasing the capacities by at least $25 \%$ resulted in all 25 trips consisting of two stops, with a total of 50 served demand points.

In Figures 5 and 6 below, it is evident that the model's increased battery and payload capacities allowed for coverage of more demand points. Additionally, many points that were located further away from the center of the Portland Metro Area were still covered. 


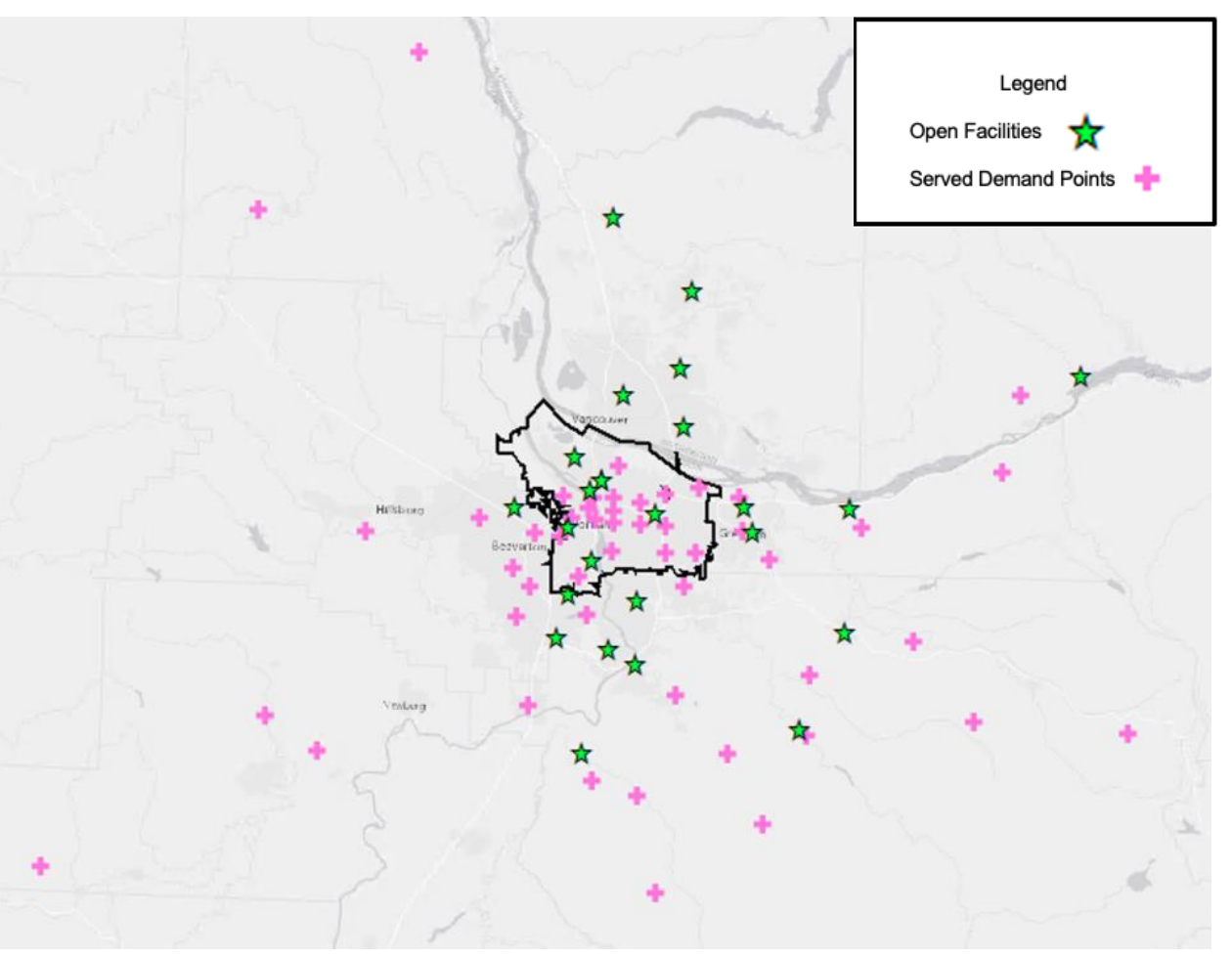

Figure 5: 25 Open Facilities, 125\% Battery and Payload Capacities

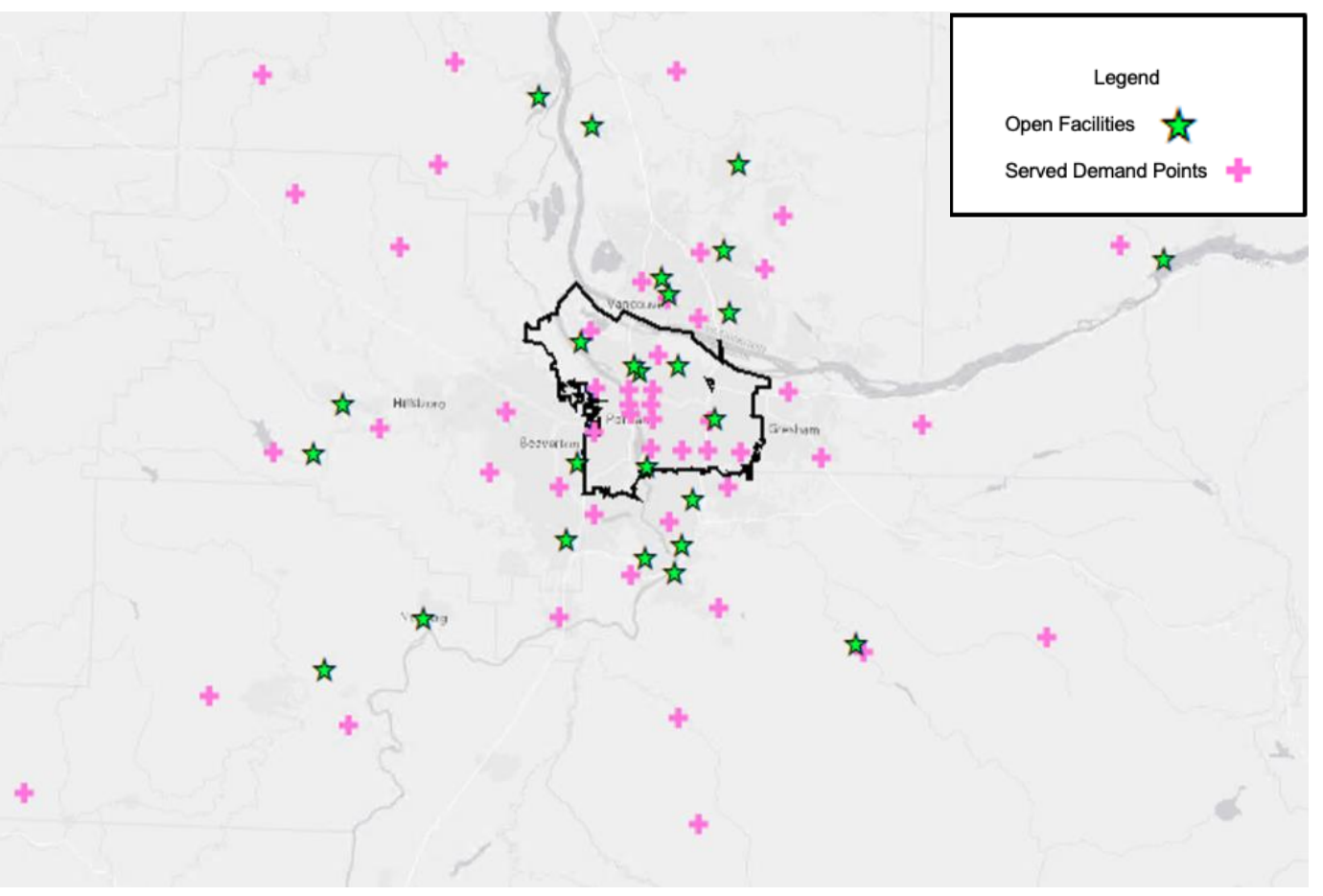

Figure 6: 25 Open Facilities, 150\% Battery and Payload Capacities 


\subsection{CONCLUSION}

In conclusion, optimization can be utilized in multiple applications, including facility location problems, freight routing problems, among numerous others. It allows a problem to be consolidated into a set of linear relationships, making it possible to find the most optimal solution to the applicable problem. This optimal solution may vary depending on the problem's objective - in this paper, the problem's objective was to maximize the demand covered by locating and opening facilities and planning drone routes for multi-stop deliveries. The drones were rangeconstrained, with battery consumption as a function of the distance traveled and the load carried. There was no drone allocation in this problem - the goal was to simulate facility locations and multi-stop trip routes for medical equipment deliveries. This problem studied various model scenarios with facility and demand points located in the Portland Metropolitan Area.

The initial model scenario tested the formulation with 15, 25, and 60 maximum opened facilities and $100 \%$ drone battery capacity. The results displayed that increasing the number of open facilities by $36.9 \%$ increased demand coverage by $55.5 \%$. Additionally, there were several routed trips in each open facility variation that were limited to a single stop. This limitation was due to the battery and payload constraints, which led to the testing of several other scenarios to compare results. After the battery capacity was increased to $150 \%$, the demand coverage remained very similar in all three facility variations. However, the total distance travelled on a trip increased

significantly. In the 25 -facility scenario, the total distance traveled with $150 \%$ battery capacity was 175 miles greater than that with $100 \%$ battery capacity. In the 60 -facility scenario, the total distance traveled was 474 miles greater. Because the demand coverage was not significantly improved with increased battery capacity, another scenario was tested with incrementally increasing battery and payload capacities. The results displayed that a $25 \%$ increase in battery and payload capacity with multiple stops per trip led to an increase of $11.8 \%$ in demand coverage, and a 50\% increase in both capacities led to an increase of $19.85 \%$ in total demand coverage. There are many future applications that can expand on this formulation. This model can be reformatted to account for capacitated facilities, limited to the amount of demand that they can serve (Chauhan et al., 2019). It can also be expanded to look at drone delivery trips with more than two stops per route. Finally, the battery consumption constraints can be elaborated on by considering effects of various weather scenarios and wind patterns on drone performance (Chauhan et al., 2020). 


\subsection{REFERENCES}

Bailey, S. 2021. "Drones could help fight coronavirus by air-dropping medical supplies." $C N N$ Business. https://www.cnn.com/2020/04/28/tech/zipline-drones-coronavirus-spc-int//index.html.

Campbell, J., Sweeney, D., Zhang, J. 2017. "Strategic Design for Delivery with Trucks and Drones." ResearchGate.

www.researchgate.net/publication/316169890_Strategic_Design_for_Delivery_with_Trucks_and Drones.

Chauhan, D., Unnikrishnan, A., Figliozzi, M. 2019. "Maximum coverage capacitated facility location problem with range constrained drones." Transportation Research Part C: Emerging Technologies, 99, 1-18. https://doi.org/10.1016/j.trc.2018.12.001.

Chauhan, D., Unnikrishnan, A., Figliozzi, M., Boyles, S. (2020). "Robust Maximum Coverage Facility Location Problem with Drones Considering Uncertainties in Battery Availability and Consumption." Transportation Research Record: Journal of the Transportation Research Board, 2675 (2), 25-39. https://doi.org/10.1177/0361198120968094.

Church, R., Revelle, C. 1974. "The maximal covering location problem.” Papers of the Regional Science Association, 32, 101-118. https://doi.org/10.1007/BF01942293.

Dayarian, I., Savelsbergh, M., Clarke, J-P. 2017. "Same-Day Delivery with Drone Resupply." Optimization Online. http://www.optimization-online.org/DB_FILE/2017/09/6206.pdf.

Dorling, K., Heinrichs, J., Messier, G. G., Magierowski, S. 2017. "Vehicle Routing Problems for Drone Delivery." IEEE Transactions on Systems, Man, and Cybernetics: Systems, 47 (1), 70-85. https://doi.org/10.1109/TSMC.2016.2582745.

Figliozzi, M. A. 2017. "Lifecycle modeling and assessment of unmanned aerial vehicles (Drones) $\mathrm{CO}_{2} \mathrm{e}$ emissions." Transportation Research Part D: Transport and Environment, 57, 251-261. https://doi.org/10.1016/j.trd.2017.09.011. 
Konert, A., Smereka, J., Szarpak, L. 2019. “The Use of Drones in Emergency Medicine: Practical and Legal Aspects." Emergency Medicine International, 2019. https://doi.org/10.1155/2019/3589792.

Kunovjanek, M., Wankmüller, C. 2021. "Containing the COVID-19 pandemic with drones Feasibility of a drone enabled back-up transport system." Transport Policy, 106, 141-152. https://doi.org/10.1016/j.tranpol.2021.03.015.

Ling, G., Draghic, N. 2019. “Aerial drones for blood delivery.” Transfusion, 59, 1608-1611. https://doi.org/10.1111/trf.15195.

Mermiri M. I., Mavrovounis, G. A., Pantazopoulos, J. N. 2020. "Drones for Automated External Defibrillator Delivery: Where Do We Stand?" J Emerg Med, 59 (5), 660-667. https://doi.org/10.1016/j.jemermed.2020.07.027.

Messar, T. Lessig, A., King, D. R. 2018. "Use of Drone Technology for Delivery of Medical Supplies During Prolonged Field Care.” J Spec Oper Med, 18 (4), 34-35.

Thiels, C. A., Aho, J. M., Zietlow, S. P., Jenkins, D. H. (2015). "Use of unmanned aerial vehicles for medical product transport." Air Med J, $34 \quad$ (2), 104-108. https://doi.org/10.1016/j.amj.2014.10.011.

U.S. Census Bureau. 2020. "ZIP Code Tabulation Areas (ZCTAs)." The United States Census Bureau. www.census.gov/programs-surveys/geography/guidance/geo-areas/zctas.html. 


\section{APPENDIX}

\section{Appendix A: Model Code - Multiple Trip Stops}

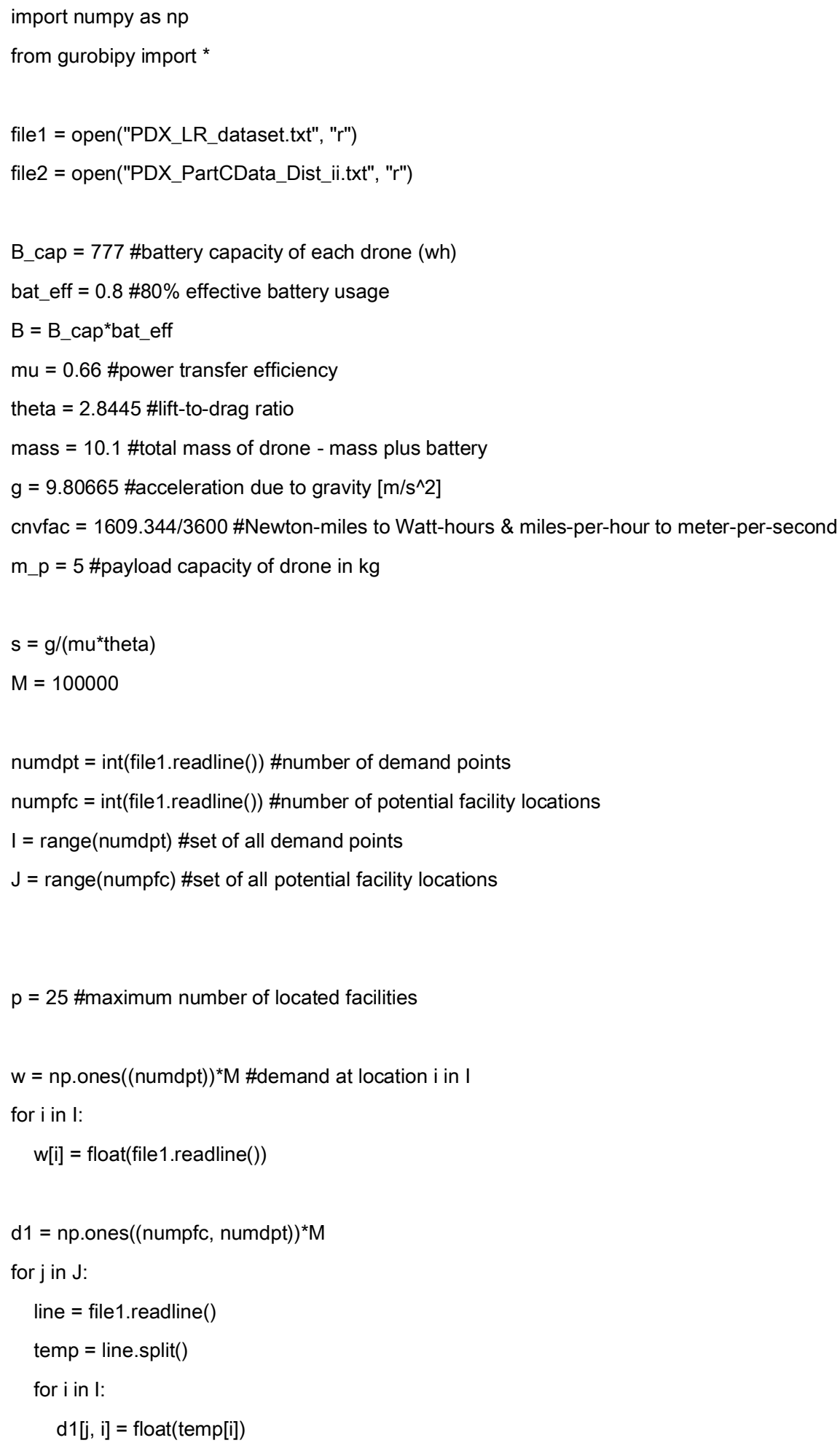




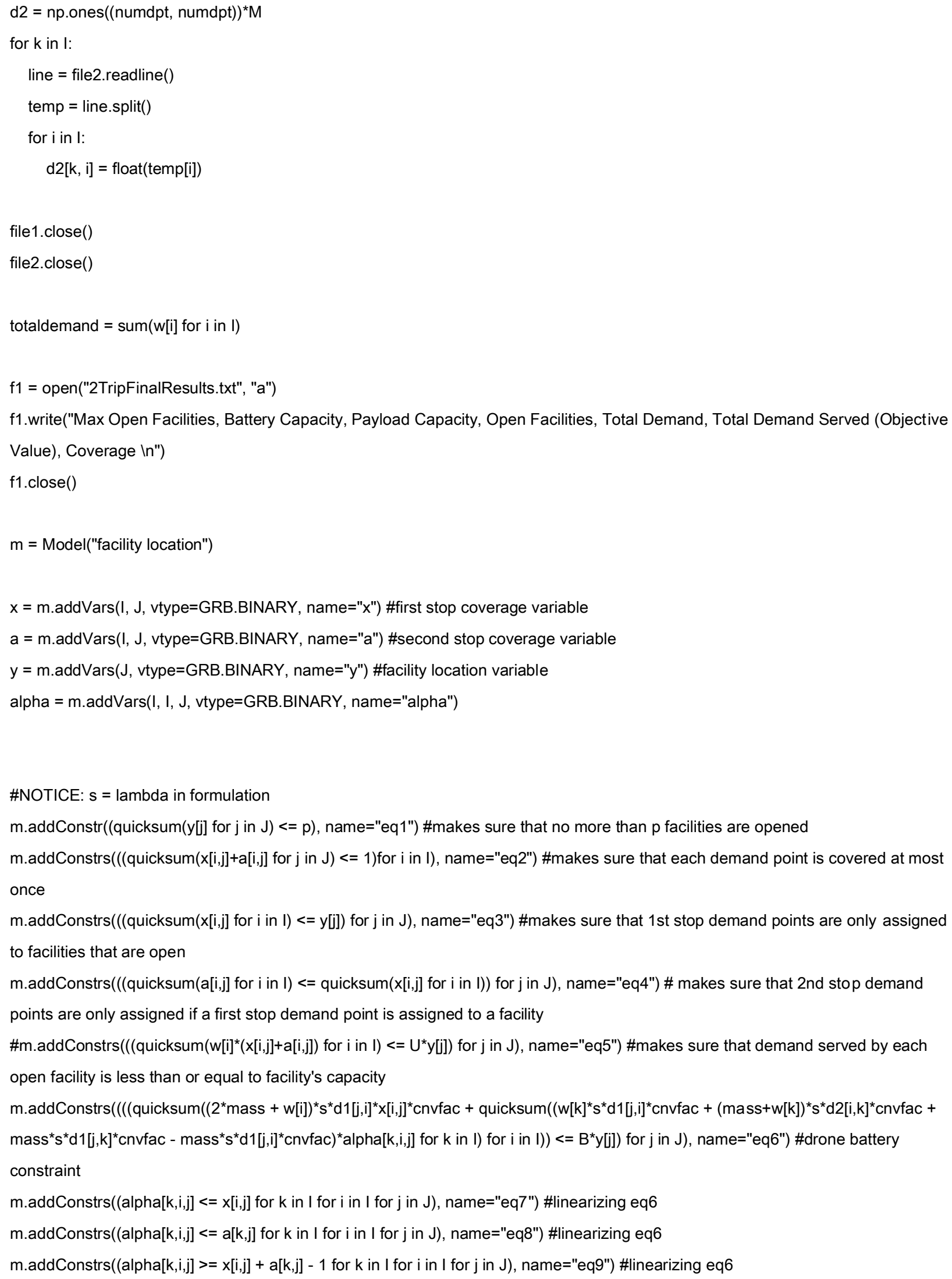




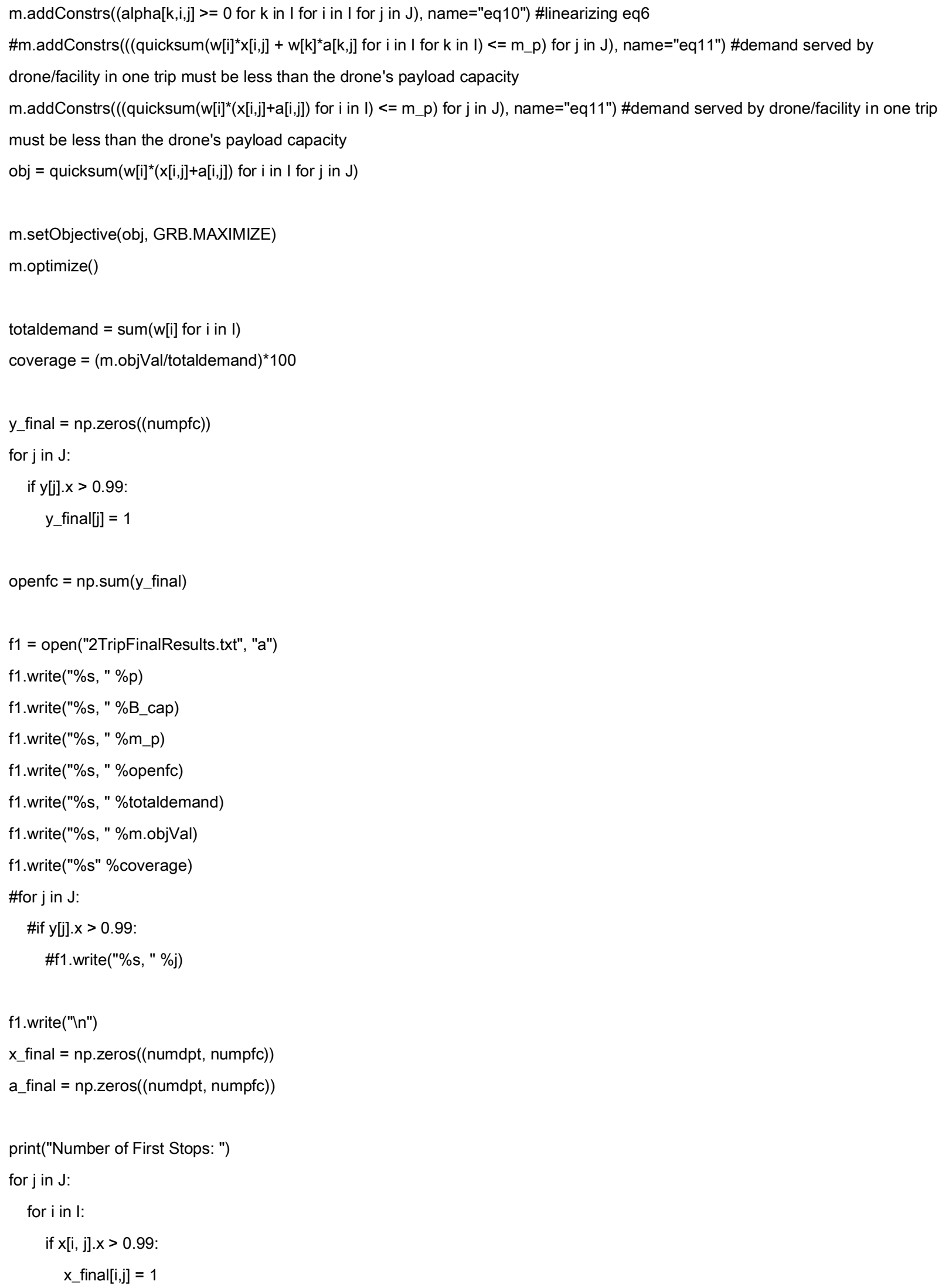




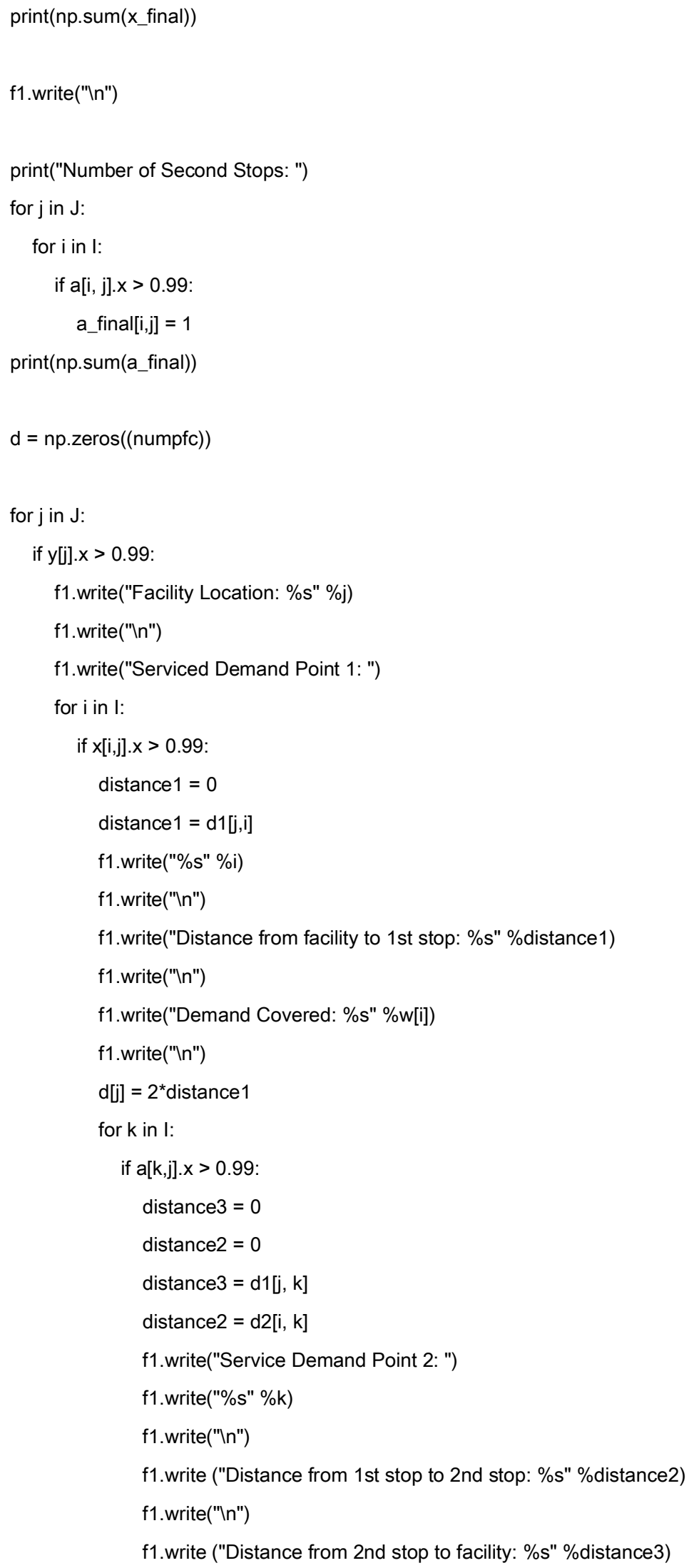


f1.write("In")
$d[j]=$ distance 1 + distance 2 + distance3

f1.write("Distance Travelled: \%s" \%d[j])

f1.write("In")

f1.write("In")

f1.write("TOTAL DISTANCE TRAVELLED: \%s miles" \%np.sum(d))

$\operatorname{print}(d)$

print(np.sum(d))

f1.write("'n")

f1.close() 